\title{
FAMILIAL POSTERIOR LENTICONUS
}

\author{
ANTHONY J. VIVIAN, CHRISTOPHER LLOYD, ISABELLE RUSSELL-EGGITT and \\ DAVID TAYLOR \\ London
}

\begin{abstract}
SUMMARY
Posterior lenticonus tends to be unilateral and there is no evidence that this is a familial condition. We report three cases of bilateral posterior lenticonus in boys. The mothers of all three cases had posterior lenticular changes, less severe than their sons. We suggest that bilateral posterior lenticonus may be inherited in an $X$ linked fashion.
\end{abstract}

Posterior lenticonus is a sharply demarcated, posterior, conical projection of the posterior capsule and cortex of the lens. It is uncommon and is usually unilateral. In a series of 135 unilateral infantile cataracts, Hiles ${ }^{1}$ found that $18 \%$ had 'posterior lenticonus. All but 1 of the cases were unilateral and there was no sex predominance. Two male patients had a positive family history of early-onset cataract, but it was not possible to confirm whether the cataracts in the relatives (in one patient a brother, and in the other patient a mother and sister) were associated with posterior lenticonus.

We report three cases of bilateral posterior lenticonus with mother-to-son transmission.

\section{CASE REPORTS}

All patients were screened for metabolic abnormalities including Lowe syndrome and found to be negative. There was no evidence of rubella infection in any patient.

\section{Case 1}

This 4-year-old boy presented when an abnormal shadow was noticed in his right pupil by his mother. On examination, right visual acuity was $1 / 60$, left visual acuity 6/12. There was a cataract affecting the

From: Hospital for Sick Children, Great Ormond Street, London WC1N 3JH, UK.

Correspondence to: Mr A. J. Vivian, Moorfields Eye Hospital, City Road, London EC1V 2PD, UK. whole posterior lens surface of the right eye and posterior lenticonus with a central posterior subcapsular opacity in the left eye (Fig. 1, above). The patient underwent right lens aspiration and after removal of the lens matter, an oval posterior lenticonus was evident in the right eye. His mother had bilateral posterior lenticonus which had not required surgery (Fig. 1, below).

\section{Case 2}

This boy presented at age 14 weeks with poor visual fixation and bilateral leucocoria. On examination, he was not fixing or following, and had manifest congenital-type nystagmus. He had posterior, axial lens opacities and at operation was found to have bilateral posterior lenticonus (Fig. 2, above). His mother had bilateral posterior capsule plaques (Fig. 2 , below) and mild myopia. His sister had normal lenses.

\section{Case 3}

This 4-year-old boy was referred when his teacher suspected poor vision. Using Sheridan-Gardiner single letters, his right visual acuity was $6 / 24$ and his left visual acuity 6/18. On examination he had bilateral posterior lenticonus with central posterior subcapsular plaques (Fig. 3, above). His mother had an 'oil-drop' reflex on retinoscopy with central fibrous strands on the posterior capsule (Fig. 3, below).

\section{DISCUSSION}

The three male cases described here had bilateral posterior lenticonus with associated cataract requiring surgical treatment. Their mothers (but not fathers) had bilateral lenticonus or posterior capsule plaques, less severe than their offspring.

$\mathrm{P}$ osterior lenticonus may be mild and remain undiagnosed; the three mothers reported above were 


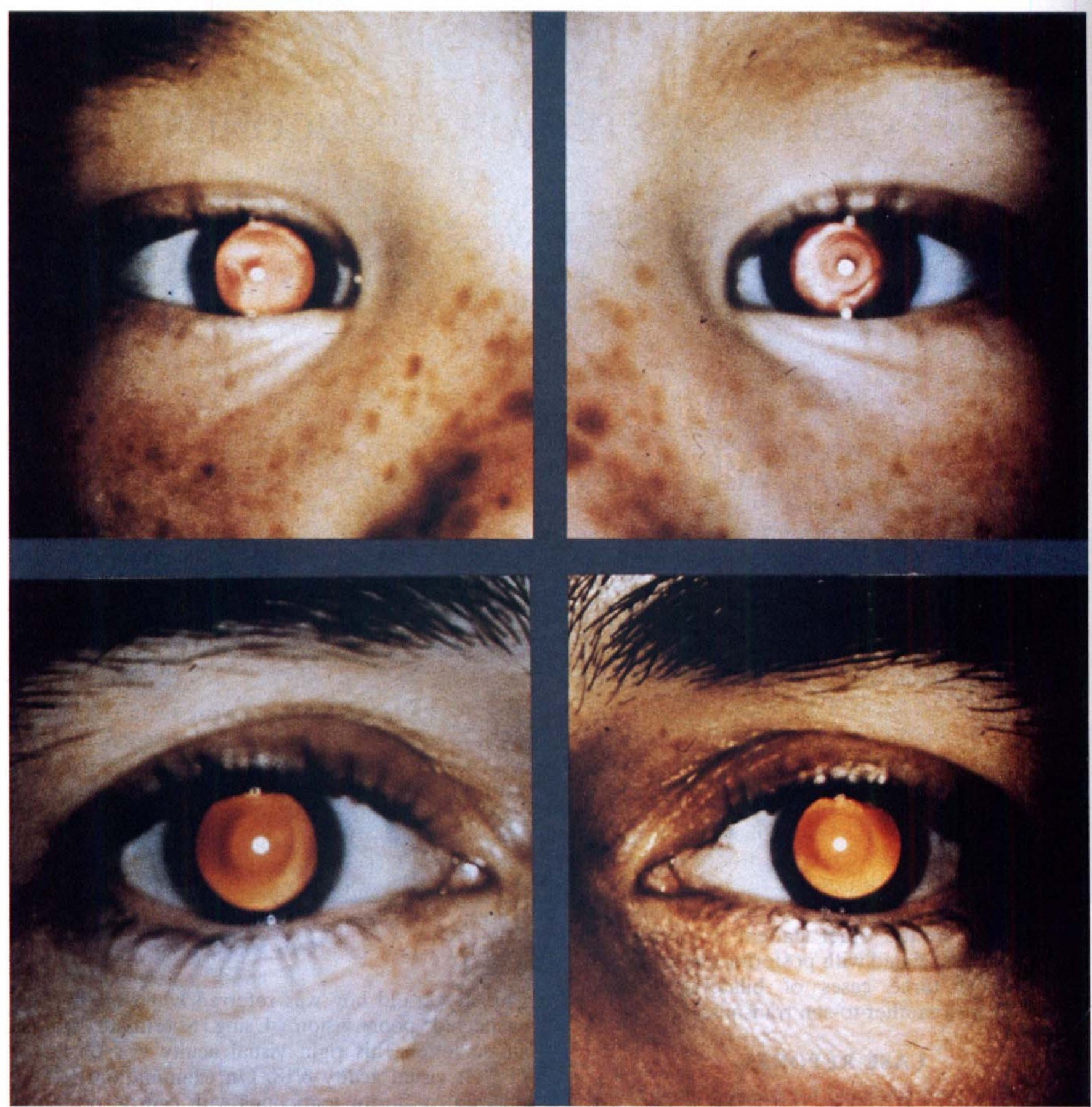

Fig. 1. Above: Right and left eyes of case 1 showing oil droplet reflex and posterior lens opacities. Below: Oil droplet reflex in the right and left eyes of the mother of case 1.

asymptomatic. If no cataract has developed, slit lamp biomicroscopy and the red reflex on retinoscopy reveal an oil globule appearance in the centre of the pupil. Cataractous change is often progressive and restricted to the posterior subcapsular region of the lens. ${ }^{2}$ Case 2 had such a cataract in association with posterior lenticonus, and was referred with leucocoria and a provisional diagnosis of retinoblastoma - similar to a case reported by Fett et al. $^{3}$

The pathogenesis of posterior lenticonus remains obscure. There is no evidence to support the early theory that it is caused by traction on the posterior capsule by the hyaloid artery. ${ }^{4}$ Khalil and Saheb ${ }^{5}$ examined the histopathology of two lenses with posterior lenticonus and showed thinning of the posterior capsule. It is most likely that posterior lenticonus develops by herniation of cortical lens fibres and posterior capsule into the vitreous at an area of posterior capsule weakness during fetal development. Capobianco and Magli $^{6}$ considered that the association between Duane's retraction 


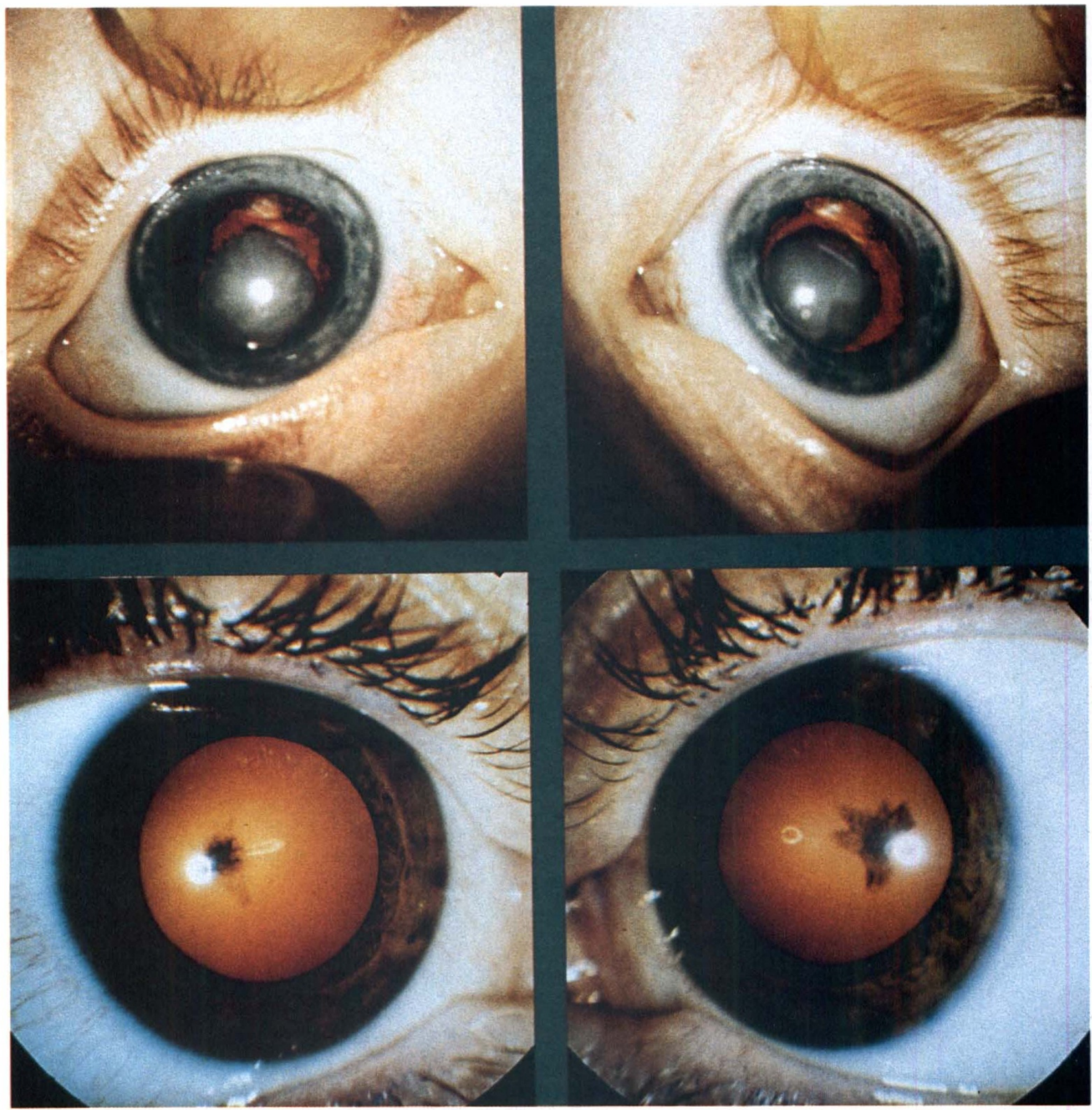

Fig. 2. Above: Posterior lenticonus and lens opacities in case 2. Below: Posterior central lens opacities in the mother of case 2.

syndrome and posterior lenticonus (also reported by Crouch and Parks $^{2}$ ) suggested dysgenesis in the middle of the third trimester of pregnancy.

Posterior lenticonus is uncommon and was reported in 1930 to occur in 1 in 100000 of the population. ${ }^{7}$ A majority of cases are unilateral and sporadic. The three cases reported above all show mother-to-son inheritance. However, as no other family members were affected, it is not possible to confirm X-linked inheritance. There was only one female sibling in the three families, and she had normal lenses. Kapoor ${ }^{8}$ reported a pedigree showing anterior lenticonus, posterior lenticonus and deafness with sex-linked inheritance. and suggested that the gene locus was on the short arm of the $X$ chromosome. The association of X-linked Lowe syndrome with posterior lenticonus ${ }^{9}$ lends support to the hypothesis that a gene on the $\mathrm{X}$ chromosome may be involved in the development of posterior lenticonus. Butler ${ }^{10}$ reported a case of bilateral posterior lenticonus in both mother and son which may well have been X-linked. Both autosomal 


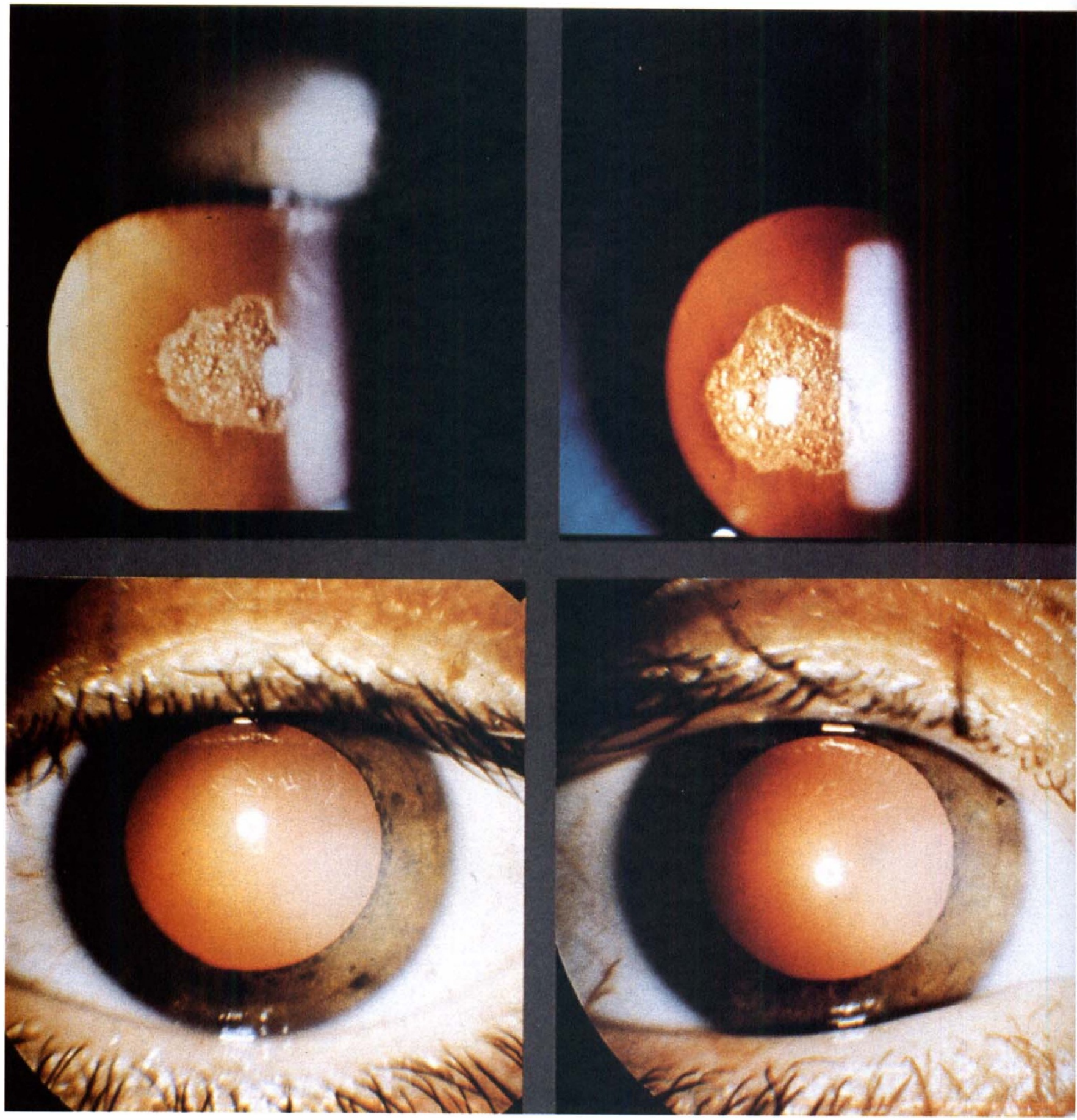

Fig. 3. Above: Lenticonus and posterior subcapsular opacities in case 3. Below: Oil droplet reflex in the mother of case 3.

dominant $^{11,12}$ and autosomal recessive ${ }^{12}$ pedigrees with posterior lenticonus have been reported.

We suggest that unilateral posterior lenticonus is a developmental abnormality and there is little evidence that it is inherited. Bilateral posterior lenticonus, however, is more likely to be inherited and the three cases reported here suggest that the gene responsible may be carried on the $\mathrm{X}$ chromosome.

Key words: Posterior lenticonus, X-linked inheritance.

\section{REFERENCES}

1. Hiles DA. Intraocular lens implantation in children with monocular cataracts. Ophthalmology 1984;91: 1231-7.

2. Crouch ER, Parks MM. Management of posterior lenticonus complicated by unilateral cataract. Am J Ophthalmol 1978;85:503-8.

3. Fett D, Paez JH, Isenberg S. Infantile leukocoria caused by posterior lenticonus. Ann Ophthalmol 1984;16:679-80. 
4. Mann I. Developmental abnormalities of the eye. Philadelphia: JB Lippincott, 1957:307.

5. Khalil M, Saheb N. Posterior lenticonus. Ophthalmology 1984;91:1429-30.

6. Capobianco S, Magli A. Retraction syndrome with posterior lenticonus. J Pediatr Ophthalmol Strabismus 1980;17:96-100.

7. Butler TH. Lenticonus posterior. Arch Ophthalmol 1930;3:425-36.

8. Kapoor S. Familial anterior and posterior lenticonus. Ophthalmologica 1979;178:186-9.
9. Tripathi RC, Cibis GW, Tripathi BJ. Pathogenesis of cataracts in patients with Lowe's syndrome. Ophthalmology 1986;93:1046-51.

10. Butler TH. Lenticonus posticum and allied anomalies at the posterior pole. Trans Ophthalmol Soc UK 1938;57:412-30.

11. Howitt D, Hornblass A. Posterior lenticonus. Am J Ophthalmol 1968;66:1133-6.

12. Pollard ZF. Familial bilateral lenticonus. Arch Ophthalmol 1983;101:1238-40. 